\title{
A intolerância religiosa em relação às Religiões Afro-brasileiras: uma realidade no cenário escolar brasileiro
}

Religious intolerance towards Afro-Brazilian religions: a reality in the Brazilian school scene

Jaqueline de Souza Gomes ${ }^{1}$

Resum o: OBrasil se apresenta ao mundo como um Estado laico, onde as muitas religiões e suas denominações convivem harmonicamente, e os fiéis manifestam suas crenças, sem que ocorra discriminação. Essa colocação, contudo, não corresponde à realidade, quando o cenário são as instituições escolares, vistas como microcosmos da sociedade, pela diversidade dos grupos sociais representados nas salas de aula desse imenso país. O presente artigo, ao priorizar como tema de suas análises a intolerância religiosa com as crianças e jovens cuja religiosidade foi construída nos terreiros e espaços das religiões afro-brasileiras, tenta discutir por meio de revisão da literatura, a discriminação que esses alunos vivenciam no cotidiano das escolas, apesar da legislação brasileira re gulamentar em todas as instâncias o direito de credo e a liberdade religiosa.

Palav ras-chaves: Intolerância Religiosa, Religiões Afro-Brasileiras, Discriminação.

Abstract: Brazil presents itself to the world as a secular state, where the many religions and their denominations coexist harmoniously, and the faithful manifest their beliefs without discrimination. However, this placement does not correspond to reality when the setting is school

Artigo recebido em: 18 de març. 2019

Aprovado em:15 de març. 2019

1 Mestranda em Ciências das Religiões - Mestrado Profissional - pela Faculdade Unida de Vitória. 
institutions, seen as microcosms of society, by the diversity of s ocial groups represented in the classrooms of this immense country. The present article, when prioritizing religious intolerance with children and young people whose religiousness was built in the terreiros and spaces of the AfroBrazilian religions, tries to discuss as a theme of their analysis the discursement that these students ex perience in daily life of schools, despite the Brazilian legislation regulating in all instances the right of creed and religious freedom.

Key-words: Religious Intolerance, Afro-Brazilian Religions, Discrimination.

\section{Introdução}

A história dos povos revela que ao longo dos tempos, o ser humano matou em nome de Deus, e apesar da evolução alcançada nesse momento contemporâneo, os homens continuam destruindo seus semelhantes por motivos religiosos. A mídia, a todo instante, mostra a existência de grupos de extermínio, formado por terroristas e radicais, que em nome de suas crenças, destroem pessoas e comunidades.

O Brasil, país que oficialmente se apresenta como católico e que, legalmente, é um país laico e aberto às diferentes crenças religiosas, tem assistido a uma guerra que se dá nos bastidores das instituições e atinge, sobretudo, as religiões afro-brasileiras, originadas do sincretismo que uniu os cultos dos africanos, aqui aportados pela escravidão, os colonizadores católicos, as crenças indígenas e mais um conjunto de influências oriundas de outras religiões.

Além dessas referências, nas últimas décadas, o Brasil assistiu ao fenômeno da ampliação das religiões evangélicas, entre elas, a Igreja Universal do Reino de Deus, que apesar das semelhanças de ritos com as religiões afro-brasileiras, contesta todos os seus cultos, opondo-se terminantemente a ver os cultos do Candomblé como manifestações religiosas, que são parte da cultura e da religiosidade brasileiras.

Por outro lado, mesmo respaldadas pela lei 10.639 de 2003, que estabelece diretrizes para a inclusão da História e Cultura AfroBrasileira nos currículos escolares, as instituições de educação no Brasil raramente trabalham conteúdos que atendam a essas exigências legais. Diante dessa realidade, a intolerância com os alunos, cuja formação religiosa é de origem afro-brasileira, torna-se visível com situações de discriminação, bulling e exclusão que 
afetam de forma direta os sentimentos desses sujeitos, cidadãos brasileiros que possuem direito de ter suas crenças.

Com base na literatura sobre o tema, o presente artigo faz uma revisão sobre esta intolerância religiosa, que tem afetado e impactado muitos grupos de alunos afro-descendentes, que em grande parte freqüentam as escolas públicas deste país, marcado pela diversidade cultural e pelas desigualdades sociais e, que em razão dessa realidade, jamais deveria discriminar pessoas com idéias, crenças e saberes diferentes.

As discussões sobre intolerância religiosa não se reduzem ao discurso e às instituições que discriminam os que não processam a mesma fé, ela penetra no ideário político, social, cultural e histórico que atravessa o movimento cotidiano dos brasileiros, assim como os espaços da vida.

\section{A intolerância religiosa e suas origens sócio- históricas}

A intolerância religiosa discrimina, exclui, segrega, aprisiona e transforma semelhantes em inimigos, gera radicalismos, ódios e desumaniza aqueles, que em nome de suas crenças e deuses, encarnados ou não, matam e aterrorizam os que pertencem a sua mesma espécie. As raízes da intolerância religiosa encontram-se na história dos povos e de suas crenças.

Segundo Silva, essa intolerância no campo religioso surge com maior visibilidade na transição do politeísmo para os monoteísmos, e mesmo a história das religiões monoteístas é marcada por momentos de intolerância, na medida em que a crença em um Deus único leva, consequentemente, a não aceitação de religiões que cultivam vários deuses ${ }^{2}$.

Antonio Ozaí da Silva comenta que:

A intolerância enraíza-se na transição do politeísmo para os monoteísmos. A história das religiões monoteístas indica momentos de convivência respeitosa, mas também períodos de intolerância intra-religião e as diversas religiões. Estas, na medida em que exige o predomínio de

2 SILVA, Vagner Gonçalves da. Intolerância religiosa: impactos do neopentecostalismo no campo religioso afro-brasileiro. São Paulo: Edusp, 2007. 
um Deus único, são inerentemente resistentes à existência de outras divindades 3 .

Os autores em tela ainda discutem o fato que, mesmo religiões monoteístas que possuem o mesmo Deus, como é o caso do judaísmo, do cristianismo e do islamismo, com o tempo, tornam-se inimigas, em razão da intolerância com as diferenças culturais, de ritos e de visões diversas, muitas vezes, sobre os mesmos fenômenos. Nesses conflitos, questões de natureza histórica, política e cultural interferem nas cisões que ocorrem através dos tempos.

Ao abordar as causas da intolerância religiosa, Rouanet defende que uma delas se enraíza na própria natureza humana, quando tendemos a nos identificar com o grupo a que pertencemos e depreciamos os valores, ideais e realizacões do grupo rival e sobrevalorizamos nosso grupo, sendo intolerantes com a alteridade. Outra causa para a intolerância religiosa seria o fator político, como foi o caso do Estado francês na época das guerras de religião, do Estado alemão durante o nazismo, ou do Estado soviético no período stalinista. Ainda para este autor, fatores sociais como a miséria, o desemprego e a perda de identidade resultante da migracão podem reforçar a intolerância, assim como o bombardeio ideológico da indústria cultural e a erosão dos valores tradicionais em consequência do processo de globalização 4 .

Bethencourt, ao comentar a Inquisição, diz que seus tribunais foram criados pelo Papa, que por sua vez delegou seus poderes de perseguição da heresia a agentes especializados desde as primeiras décadas do século XIII, mas se consolidou com o apoio do poder político dos monarcas 5 .

Conforme posição de Silva ${ }^{6}$ e Bethencourt7, "guerras religiosas" e as perseguições aos crentes não se restringem ao âmbito das querelas dogmáticas referentes à percepção do sagrado, mas dizem respeito aos interesses profanos dos poderes instituídos e às disputas pela soberania política”. Esta abordagem retrata que a política se torna sacralizada, configurando uma espécie de guerra

\footnotetext{
3 SILVA, Antonio Ozaí da. Sobre a Intolerância Religiosa. Revista Espaço Acadêmico, n.203, abril de 2018.p.65.

4 ROUANET, Sergio Paulo. O Eros da diferença. Folha de S. Paulo, São Paulo. Caderno Mais, o9 fev.2003.

5 BETHENCOU RT, Francisco. História das Inquisições: Portugal, Espanha e Itália do século XV. São Paulo: Companhia das Letras, 2000.

${ }^{6}$ SILVA, 2018, p.83.

7 BETHENCOURT, 2000, p.93.
} 
santa, que cede lugar à intolerância religiosa, mesmo havendo espaços para o diálogo tolerante.

Essa espécie de tolerância laica tem marcado a história recente das religiões, em muitas situações de forma sutil, em uma espécie de violência psicológica, simbólica, que no Brasil atinge, principalmente, as religiões afro-brasileiras, estigmatizadas pelo passado e por sua origem, visto terem nascido das crenças dos negros escravizados vindo da África.

Amstrong considera que esta intolerância esteve presente, não só nos representantes do cristianismo católico, mas também nos originários das igrejas e religiões protestantes. Segundo os historiadores, tanto a reforma quanto a Contra-Reforma foram guerras que revelaram horrores recíprocos realizados em nome de Deus. É a autora quem afirma:

Mesmo após sua grande ruptura, Lutero continuou aterrorizado pela morte. Parecia estar constantemente num estado de fúria latente: contra o Papa, os turcos, os judeus, as mulheres, os camponeses rebeldes, os filósofos escolásticos e cada um de seus opositores teológicos ${ }^{8}$.

A intolerância religiosa se manifesta nas mais diversas direções e crenças. Mais recentemente, o mundo assistiu e ainda assiste a guerra santa do Islã, a "Jihad", que fundada nas teses do "Corão" toma seus princípios ao pé da letra, criando grupos que se matam, causam "terror" e deturpam a tolerância pregada pelo seu líder, Maomé, à época em que pregou suas idéias.

Ao longo dos tempos, filósofos como Locke, que viveu no século XVI, Voltaire e outros falaram da intolerância religiosa mostrando o absurdo da violência contra seus semelhantes pelos homens, quando a fé dá origem a posições dogmáticas e ao ódio, que separa e exclui seres da mesma espécie.

Reconhecer que a intolerância religiosa se confunde com a intolerância laica do poder político-civil, significa dizer que desde a Antiguidade com seus deuses, chegando ao monoteísmo da Idade Média, os representantes religiosos sempre fizeram pactos com o

8 AMSTRONG, Karen. A Bíblia: uma biografia. Rio de Janeiro: Zahar, 2007 . 
poder político e social utilizando a fé e as crenças dos fiéis, em nome de interesses menores e por vezes, mesquinhos.

No caso específico que é foco desse artigo, a intolerância com as religiões afro-brasileiras traz à tona a discriminação racial e a intolerância com as crenças de pessoas, que no âmbito da sociedade de classes são consideradas como "seres inferiores", mesmo que esse olhar ocorra em uma sociedade que se diz laica e aberta à pluralidade religiosa.

\title{
1. A intolerância religiosa em relação às religiões afro-brasileiras nos espaços escolares
}

Os currículos brasileiros, e neles se incluem as últimas propostas de mudança presentes na Base nacional Comum curricular (BNCC), sempre se apresentaram como laicos e plurais no tocante ao ensino religioso. Contudo, em nome de uma suposta neutralidade, isto não ocorre na prática, sobretudo quando se sabe que alunos matriculados em escolas públicas sofrem bulling em conseqüência da afirmação da opção religiosa por religiões afrobrasileiras.

Miranda e Pereira ${ }^{9}$ ao citarem Nora $^{10}$ e Pollak dizem:

\begin{abstract}
A temática religiosa na contemporaneidade tem se mostrado - tanto no plano nacional quanto internacional - como uma das dimensões da cultura mais afetadas, cotidianamente, pelos efeitos corrosivos das práticas de discriminação e intolerância. Em todos os casos assistimos a tais efeitos de modo sempre mediado pela amplificação assumida pelas estratégias midiáticas. São discursos e ações presentes nos veículos que produzem e repetem notícias que informam, selecionam e, por vezes, demarcam acontecimentos que se monumentalizam em meio a opções intencionais pelo esquecimento e/ou pelo silenciamento segundo aquilo que pauta a dinâmica da Memória ${ }^{11}$.
\end{abstract}

9 MIRANDA, Sonia Regina; PEREIRA, Júnia Sales. Laicização e Intolerância Religiosa: desafios para a História ensinada. Revista Educação \& Realidade, Porto Alegre, v. 42, n. 1, p. 99-120. jan./mar. 2017.

10 NORA, Pierre. Entre Memórias e História: a problemática dos lugares. Projeto História, São Paulo, PUCSP, v. 10, p. 07 -28, jul./dez. 1993.

11 POLLAK, Michel. Memória, Esquecimento, Silêncio. Estudos Históricos, Rio de Janeiro, v. 2, n. 3, p. 3-15, 1989. 
No caso da população afrodescendente, que traz em sua história, a origem dos povos africanos em sua ancestralidade, com sua cultura própria, crenças, tradições, que se somaram aos brasileiros, já misturados pela presença da população nativa, as tribos indígenas, formando essa mistura que é o povo brasileiro, antes da questão étnica ou mesmo religiosa, são cidadãos brasileiros portadores de direitos.

Nas três últimas décadas, sobretudo a investida do lobby religioso evangélico, em nome de atitudes aparentemente neutras, lançou uma espécie de campanha que inclui mídias e cultos inflamados, na direção das religiões afro-brasileiras, em nome de uma pseudo moral, contraditória na medida em que articulava, em um mesmo discurso, interesses econômicos, preceitos bíblicos, rituais espíritas e outras estratégias para angariar novos fiéis.

Esta realidade ganha visibilidade nas escolas, cujo currículo, apesar da vigência da lei 10.639 de 2003, que além de incluir a história africana nos conteúdos curriculares das escolas básicas, também se refere aos direitos da população afrodescendente aos seus credos, costumes e tradições, sendo que a lei 11.645 de 2008 estende esses direitos aos indígenas brasileiros.

Essas legislações, muitas vezes negligenciadas pelos sistemas de ensino, conforme analisa Souza ${ }^{12}$ em sua tese, ignoram o que Silva ${ }^{13}$ comenta sobre as relações entre currículo e cultura, no momento que enfatiza ser impossível um modelo de ensino que defenda a homogeneidade, visto que as escolas são espaços onde as diferenças se tornam visíveis, revelando a pluralidade de idéias, valores e atitudes que mostram a diversidade em todas as suas nuances.

Conforme análise de Cury, o desafio da educação, no tocante ao ensino religioso nas escolas públicas, é o fato de que apesar das escolas brasileiras se apresentarem não-confessionais, a presença dos símbolos católicos é frequente, principalmente pelo fato de vivermos em um Estado laico, onde o histórico da religião católica

12 SOUZA, Eliane Almeida de. A lei1 o.639/o3 na formação de professores e o pertencimento étnico-racial em escolas públicas de Porto Alegre. 2009. 140f. Dissertação (Mestrado em Educação) - Universidade Federal do Rio Grande do Sul, Porto Alegre, 2009.

13 SILVA, 2007 , p.273. 
como religião oficial ainda se mostra marcante nas salas de aula do país, apesar da investida evangélica ${ }^{14}$.

Miranda e Pereira consideram que, de certa forma, a escola dessacraliza o fenômeno religioso, visto que sua função social é outra e entre os conhecimentos que se encontram no rol dos seus objetivos não se encontram as manifestações religiosas e suas práticas, mesmo que estas ganhem visibilidade através da cultura de grupos de alunos, cujos valores se mostram nas relações que ocorrem nas muitas escolas desse país ${ }^{15}$.

Desta forma, o que a escola não pode deixar de lado, é o fato de que por questões legais e por questões de humanidade, crianças, adolescentes, jovens e adultos não podem ser discriminados por suas escolhas, seja de gênero, religião, posições diferentes sobre qualquer outra questão. O encontro religioso entre Eu e o Outro é condição para a luta contra a intolerância religiosa. Por outro lado, quando a escola exclui e discrimina afrodescendentes por quaisquer tipo de intolerância, todas as religiões saem perdendo ${ }^{16}$.

Assim, entre os muitos desafios encontra-se aquele que impele os sistemas de ensino e suas instituições a cumprirem as leis, trabalharem melhor as relações entre currículo e cultura e, sobretudo, cultivarem o diálogo da tolerância, para que os alunos afrodescendentes possam livremente falar e exercitar seus valores religiosos e os princípios dos credos de seus ancestrais.

\section{A intolerância com as religiões afrodescendentes}

Quando no ano de 2014, um grupo de pesquisadores da Universidade Estadual Fluminense (UENF), do Laboratório de diversidade e práticas culturais optaram por realizar um levantamento do número de terreiros de umbanda/candomblé no município de Campos dos Goytacazes, a Igreja Universal do Reino de Deus (IURD) manifestou-se contrariamente à pesquisa, de forma bastante sutil, através de alguns de seus representantes ${ }^{17}$.

\footnotetext{
14 CURY, Carlos Roberto Jamil. Ensino religioso na escola pública: o retorno de uma polêmica recorrente. Revista Brasileira de Educação, Rio de Janeiro, n. 27, set./dez. 2004.

15 MIRANDA e PEREIRA, 2017, p.110.

16 SOUZA, 2009 , p.124.

17 LIMA, Lana Lage da Gama, VIEIRA SILVA, Leonardo, SANTOS, Diego Henrique Nascimento, PAULA, Yann Almeida Belmont. As religiões afrobrasileiras em Campos dos Goytacazes: preservar, dar visibilidade e combater a discriminação. UENF, 2015.
} 
Por outro lado, os presidentes das entidades possuidoras de terreiros se uniram, reconhecendo a importância da pesquisa e principalmente, da valorização das manifestações religiosas de origem africana, que lutam por representatividade em uma sociedade conservadora e preconceituosa, cuja região teve um dos focos mais cruéis da escravidão no Estado do Rio de Janeiro.

Ações como essa pesquisa, à época respaldada por instituições como órgãos do município, contribuem para que as matrizes africanas cheguem às escolas com mais força, apoiadas pela pesquisa acadêmica. Por outro lado, por mais que a Igreja Universal se oponha às práticas religiosas afro-brasileiras, estudos feitos por Julio Cezar Benedito apontam para a semelhança de ritos entre estes dois pólos da religiosidade brasileira. Sobre isto, ele diz:

\section{(...) é com os que a Igreja Universal do Reino de Deus realiza sua maior simbiose ritualística. Dos cânticos aos patuás, passando pelos exorcismos, os universais se apossam de um grande número de atitudes e símbolos tradicionalmente vinculados às religiões e seitas de origem ou inspiração africana. Ao contrário das igrejas protestantes históricas que mantêm grande parte de sua liturgia religiosa ligada ao catolicismo original, os universais aplicam às suas práticas muitos dos rituais e símbolos herdados dos afro-brasileiros ${ }^{18}$.}

Diante dessa realidade, parece inconcebível que criancas e jovens afrodescendentes que professam religiões de matriz africana sejam discriminados nas escolas, pelos evangélicos, muitos deles da Igreia Universal. Segundo o Bispo Dom Hélder Câmara ${ }^{19}$, já falecido, "o ideal religioso deveria ser a irmanação de todos os fiéis que têm no cristianismo o ponto convergente de sua fé." Para este humanista, a busca espiritual, como experiência individual e coletiva, iamais poderia separar os semelhantes, mas sim uni-los, porque são todos pecadores.

Por outro lado, caso a legislação brasileira - Constituição Federal de 1988, Lei 10.639 de 2003 e Lei 11.645 de 2008 - fossem cumpridas, talvez houvesse menos radicalismo nas demonstrações

\footnotetext{
18 BENEDITO, Julio Cezar. Religiões e religiosidades popular es. o conflito religioso e a simbiose de ritos e performances entre neopentecostais e .Universitas Humanística, n. 61, p. 249, 2006.

19 CÂMARA, Dom Hélder. A Universalidade Cristã. São Paulo: Edições Paulinas, 1989.
} 
de discriminação e exclusão dos alunos que atestam ter religiões afro-brasileiras como crença. Mas, na prática, não deveria haver nenhuma forma de discriminação, por tratar-se de direito à liberdade de escolha de credo $^{20}$.

As criancas afrodescendentes que assumem sua religião na escola, em muitas situações, sofrem preconceito duplo e até triplo, pois são discriminadas pela cor, pela aparência com seus cabelos afros e pela religião. Em um país, que iá se apresentou ao mundo sob o mito da igualdade/democracia racial, da pluralidade religiosa e de tantas outras expressões falsas, conforme sinaliza Souza, deveria assumir que não cumpre suas leis com o mesmo rigor que separa e exclui a cultura religiosa dos africanos e seus descendentes ${ }^{21}$.

$\mathrm{O}$ trabalho de Eliane Almeida de Souza ainda mostra, com experiências reais extraídas de sua pesquisa, que até mesmo criancas negras pouco conhecem da história de sua gente e muito menos dos orixás, símbolos e rituais de sua religião. Esta realidade aponta para a gravidade de impor a criancas e jovens os valores religiosos sem explicar as razões pelas quais existem.

Cultura e religião afro-brasileira se fundem e como são parte da história do país, é essencial apresentá-las por força de lei, a todos os alunos, a história das religiões afro-brasileiras e os princípios religiosos que regem a religião de seus ancestrais. Em ambos os casos, o direito de conhecer é inalienável para todos os estudantes da Escola Básica no Brasil.

\section{Considerações finais}

A intolerância é algo abominável em qualquer situação que envolva grupos humanos. Quando esta intolerância envolve crianças e jovens no espaço escolar, essa intolerância se torna inadmissível, sobretudo ao envolver escolhas religiosas. Contudo, os alunos matriculados nas escolas públicas, que são afrodescendentes e admitem pertencer às religiões afro-brasileiras, sofrem discriminação e exclusão social, tornando-se vítimas da intolerância religiosa.

Mesmo que no Brasil existam leis que incluem estudos sobre a história dos africanos, que aqui chegaram em grande parte como escravos, estas legislacões não são cumpridas e os alunos, em geral, desconhecem a trajetória de anulação de direitos e de total exclusão dessas populações, assim como os sofrimentos, dores e proibições

20 SOUZA, 2009 , p.36.

${ }_{21}$ SOUZA, 2009, p.43. 
sofridas por essa gente que muito contribuiu para a formação do povo brasileiro.

No caso das religiões, como o candomblé e a umbanda, por mais que se viva em um país que defende a liberdade e a pluralidade religiosa, estas são atacadas como religiões inferiores, e nas últimas décadas foram alvo da depreciação e da campanha ofensiva da Igreja Universal do Reino de Deus.

Reconhecer que é urgente cumprir as leis que defendem a inclusão da história dos africanos e dos indígenas nos currículos escolares, pode ser um caminho para o diálogo inter-religioso, assim como para uma aceitação maior da religião dos alunos afrodescendentes, que têm o direito de praticar a fé de seus ancestrais.

\section{Referências}

AMSTRONG, Karen. A Bíblia: uma biografia. Rio de Janeiro: Zahar, 2007.

BENEDITO, Julio Cezar. Religiões e religiosidades populares. o conflito religioso e a simbiose de ritos e performances entre neopentecostais e .Universitas Humanística, n. 61, p. 249, 2006.

BETHENCOURT, Francisco. História das Inquisições: Portugal, Espanha e Itália do século XV. São Paulo: Companhia das Letras, 2000

BRASIL. Base Nacional Comum curricular. BNCC. MEC/CNE, dezembro de 2017.

. Lei 10.639 de 2003. Altera a Lei ${ }^{0}$ 9394/1996, para incluir no Currículo Oficial da Rede Oficial de Ensino, a obrigatoriedade da temática "História e Cultura AfroBrasileira”. Diário Oficial da União, 10 de jan., 2003.

. Lei 11.645/2008. Altera a Lei 9394/96 para incluir nos currículos oficiais a "História e Cultura Afro-Brasileira e Indígena”. Diário oficial da União, 11 de mar., 2008. 
CURY, Carlos Roberto Jamil. Ensino religioso na escola pública: o retorno de uma polêmica recorrente. Revista Brasileira de Educação, Rio de Janeiro, n. 27, set./dez. 2004.

CÂMARA, Dom Hélder. A Universalidade Cristã. São Paulo: Edições Paulinas, 1989.

LIMA, Lana Lage da Gama, VIEIRA SILVA, Leonardo, SANTOS, Diego Henrique Nascimento, PAULA, Yann Almeida Belmont. As religiões afro-brasileiras em Campos dos Goytacazes: preservar, dar visibilidade e combater a discriminação. UENF, 2015.

MIRANDA, Sonia Regina; PEREIRA, Júnia Sales. Laicização e Intolerância Religiosa: desafios para a História ensinada. Revista Educação \& Realidade, Porto Alegre, v. 42, n. 1, p. 99-120. jan./mar. 2017.

NORA, Pierre. Entre Memórias e História: a problemática dos lugares. Projeto História, São Paulo, PUCSP, v. 10, p. 07-28, jul./dez. 1993.

POLLAK, Michel. Memória, Esquecimento, Silêncio. Estudos Históricos, Rio de Janeiro, v. 2, n. 3, p. 3-15, 1989.

ROUANET, Sergio Paulo. O Eros da diferença. Folha de $S$. Paulo, São Paulo. Caderno Mais, o9 fev.2003.

SILVA, Antonio Ozaí da. Sobre a Intolerância Religiosa. Revista Espaço Acadêmico, n.203, abril de 2018.

SILVA, Vagner Gonçalves da. Intolerância religiosa: impactos do neopentecostalismo no campo religioso afro-brasileiro. São Paulo: Edusp, 2007.

SOUZA, Eliane Almeida de. A lei 10.639/o3 na formação de professores e o pertencimento étnico-racial em escolas públicas de Porto Alegre. 2009. 140f. Dissertação (Mestrado em Educação) - Universidade Federal do Rio Grande do Sul, Porto Alegre, 2009. 